\title{
PERFOMANCE EVALUATION ON LIGHT TRANSMITTING CONCRETE (TRANSLUCENT CONCRETE)
}

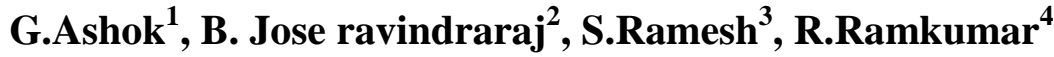 \\ ${ }^{1} P G$ Scholar, Structural Engineering, Prist University Thanjavur, Tamil Nadu, India. \\ ${ }^{2}$ Assistant Professor, Civil Engineering, Prist University Thanjavur, Tamil Nadu, India. \\ ${ }^{3} P G$ Scholar, Structural Engineering, Prist University Thanjavur, Tamil Nadu, India. \\ ${ }^{4}$ PG Scholar, Structural Engineering, Prist University Thanjavur, Tamil Nadu, India.
}

\begin{abstract}
Concrete structural components exist in buildings in different forms and shapes. This concrete plays vital role in construction industry and at present scenario it is important produce concrete structures without affecting the environment. So, to produce sustainable concrete a new development is necessary to deal with. Therefore light transmitting concrete is one option that utilise the natural light source effectively and at the same time satisfying the strength and aesthetic needs. This project deals with producing light transmitting blocks using the plastic optic fiber (pof) in cement mortar and concrete. The plastic optical fibers is embedded with concrete to be a translucent concrete. Fibres (by weight) are sandwiched between each layer of mortar and concrete and comparative study carryout on compressive strength of the normal concrete and concrete with addition of pof in different percentage. The result indicates that, compressive strength of light transmitting concrete is equal to the normal concrete strength. Light transmittance through these concrete are found to be measured by light dependent resistor (ldr). Light transmittance ability for the cement mortar blocks samples found to be 5 to $10 \%$ in and 3 to $6 \%$ in concrete blocks. The result indicates that cement mortar blocks have high transparency than concrete blocks.
\end{abstract}

Keywords: Translucent Concrete, Plastic Fibre Optics, Light Dependend Resistor Etc...

\section{INTRODUCTION}

Nowadays, concrete is the most use building material all around, it takes on nearly any shape and forms the backbone of the variety of world's construction. It is the mixture of cement, fine aggregate and coarse aggregate. It is used to construct massive bridges, man made water ways, mega dams, super highways, the world's tallest skyscrapers and so on over all around the world. Because of its strength and durability it can be used in underground tunnels also. Even though it has many advantages, one of the biggest draw back in concrete is that it creates dark buildings, that do not effectively conduct light. There is not much natural sunlight passing through when two buildings are close together and the natural sunlight is well known. According to indian green building council accounting for 3 credits which $3 \%$ of sunlight is required in a green building. But,

This can be possible only by embedding plastic optic fibre in a concrete. The new development in concrete technology is allowing day light through the concrete blocks by embedding the plastic optic fibres.

In order to develop the green building concept, concrete may also use to transmit the light from one face to another. Generally concrete is a mix of coarse aggregate, cement and fine aggregates. Where the light transmitting concrete is little different than normal concrete which contains microconcrete and plastic optic fibres. It consists of $96 \%$ concrete and only $4 \%$ by weight of optic fibres. The chemical admixtures make this concrete stronger than normal concrete. It can be manufactured by prefabricated blocks in a standard sizes.

It is $4 \%$ of plastic optic fiber is added to gives as same as the conventional concrete strength. It shows the improvement in higher light transmitting capacity when the volume of the fiber increased by its total volume of the concrete which are very important for reducing electricity by using the day light as source.

\subsection{Fibre Optics}

It is a composition of fibre and optics, where the light are travelled in the kind of glass or plastic fiber. Optic fibers are worked in the principal of total internal reflection. When light at different angle at the interface between the core and cladding. Some light is reflected back and entered into cladding, which is known as refraction. When incident angle greater than the critical angle, no more light enters into the cladding. This is known as total internal reflection.

There are two types of fibre optics they are plastic fibre optics and glass fiber optics. But we used plastic optic fibers, because of low cost to be economical. It is an optical fiber which is made out of plastic. The core material is acrylic, and fluorinated polymers are the cladding material. Almost $96 \%$ of the cross section is the core of fibre that allows the transmission of light. As same as traditional glass fiber, pof transmits light (or data) through the core of the fiber. The core size is 100 times larger in plastic fibre optics compared to than glass fiber. 


\subsection{Plastic Optical Fibre}

It is an optical fiber which is made out of plastic. The core material is acrylic, and fluorinated polymers are the cladding material. Almost $96 \%$ of the cross section is the core of fibre that allows the transmission of light. As same as traditional glass fiber, pof transmits light (or data) through the core of the fiber. The core size is 100 times larger in plastic fibre optics compared to than glass fiber.which having the higher refractive index of value $n=1.5$ andcladding having the lower refractive index of value $n=1.4$

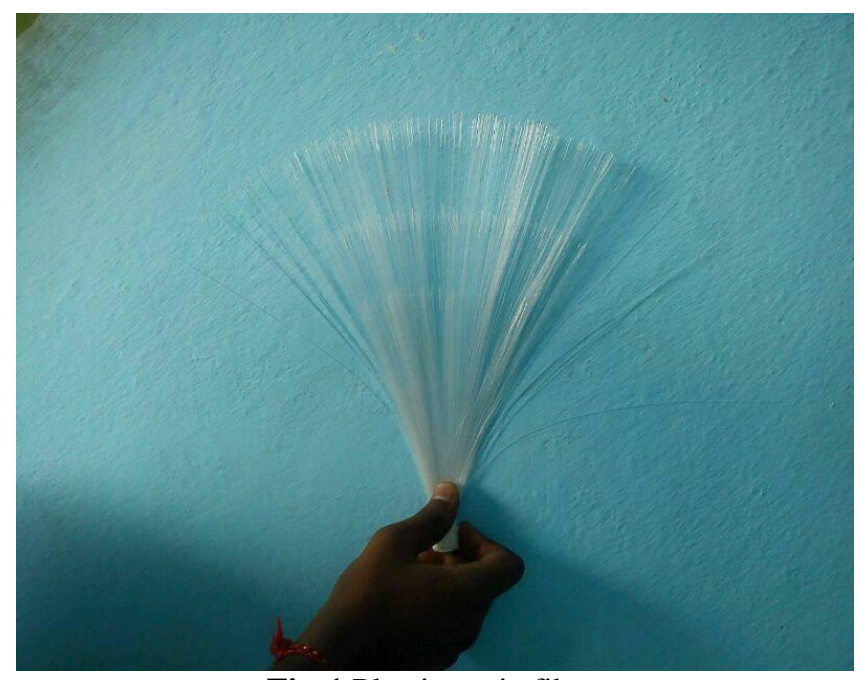

Fig-1 Plastic optic fibre

The core and cladding layer are based upon extremely pure fused silica, which is a fiber glass which almost no impurities which help to very low loss for long distance transmission. Snell's law which guides how light gets reflection and refraction

\subsection{Light Dependent Resistor (LDR)}

Ldr is also called as photo resistor or photo cell is a resistor which light to be controlled. when resistances of a photo resistor decreases with increasing incident light intensity. sometimes it exhibits photo conductivity. In this project, ldr is used to measure the light transmitting property of the concrete / cement mortar blocks.

\subsection{Objectives of the Projects}

1. To identify and study the following fresh and harden properties of translucent concrete:

- Workability of the concrete

- Concrete compresssive strength

- property of the translucent concrete

2. To compare the conventional concrete and the concrete in which plastic optic fibers are embedded

\subsection{Applications of LTC}

- Used in sidewalks

- Used at dark subway stations

- In the event of a power failure used in lighting indoor
- At roadways in speed bumps at night

- In tiles as decoratives and also in stair case

\subsection{Scope of Project}

In the current scenario, energy efficient building materials and concepts have been attracted much attention by the engineers. Usually, office buildings like it park, and commercial buildings like theatres, malls are constructed by concrete material. The luminosity of those indoor environment is completely with stand by the artificial lights which consume much electricity. Constant maintenance and repairing is needed to enhance the life cycle of those environment. There is only one way to minimize the cost of electricity in those buildings by making the concrete as a transparent, which allows the day light to inside of the building. The current approach is to achieve this kind of concrete by inducing or embedding plastic optic fiber.

This also helps to improve the architectural view of the structure as a aesthetic material and for interior walls cladding. The main purpose is to use sunlight as a light source to reduce the power consumption of illumination and to use the optical fiber to sense the stress of structures. This technology have more scope on making glowing sidewalks, and speed bumps for drivers at night.

Another approach is made to replace the traditional concrete materials, gravel, sand and cement with plastics and glass of various sizes and bind them together with transparent glue which having more scope in the manufacturing of transparent panels.

In order for this concrete to be a viable construction material, it must be able to compete economically with existing light transmitting concrete materials. This project deals specifically with the concrete embedded by the low cost plastic optic fibres.

\section{Methodology}

\subsection{General}

The following procedure is followed to make light transmitting blocks:

\subsection{Preparation of Light Transmitting Cement Mortar and Concrete Blocks:}

\subsubsection{Preparation of Mould}

Separate mould prepared to construct these blocks, the dimension of our mould is 27(l) x 27(b) x 20(h) cm. Here, length and breadth of this mould is equal to same as the length of the fibre what we using. 


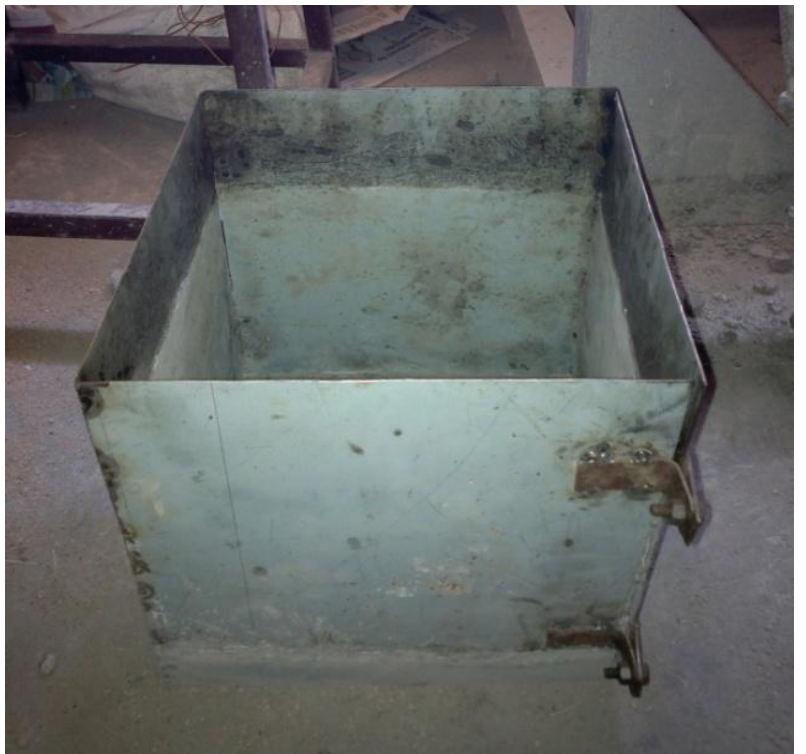

Fig-2: Prepared mould (27x27×20cm)

\subsubsection{Batching of Materials}

Batching of materials can be done by taking weight of each material using to make transparent concrete blocks. Here batching done for concrete / cement mortar and plastic optic fibres used to construct one single block.

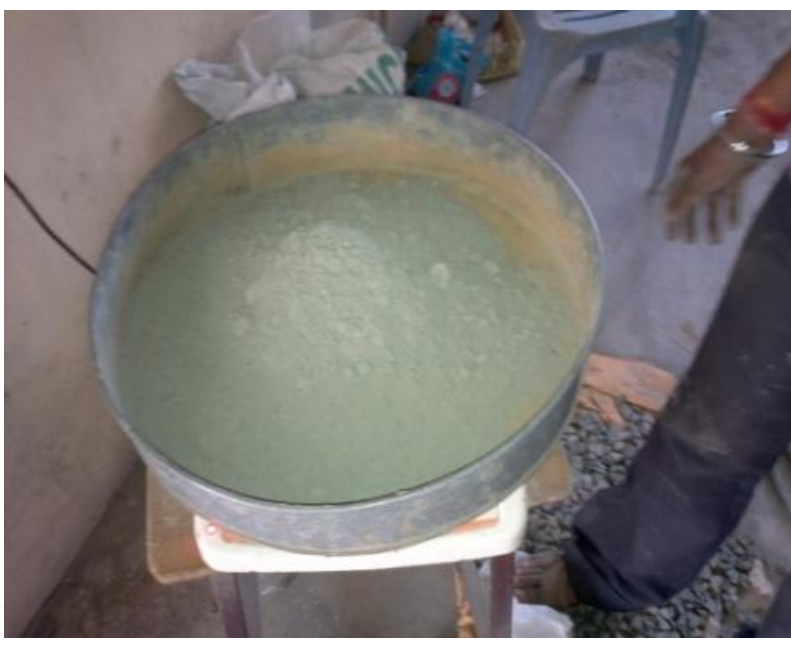

Fig-3: 53 Grade ppc cement

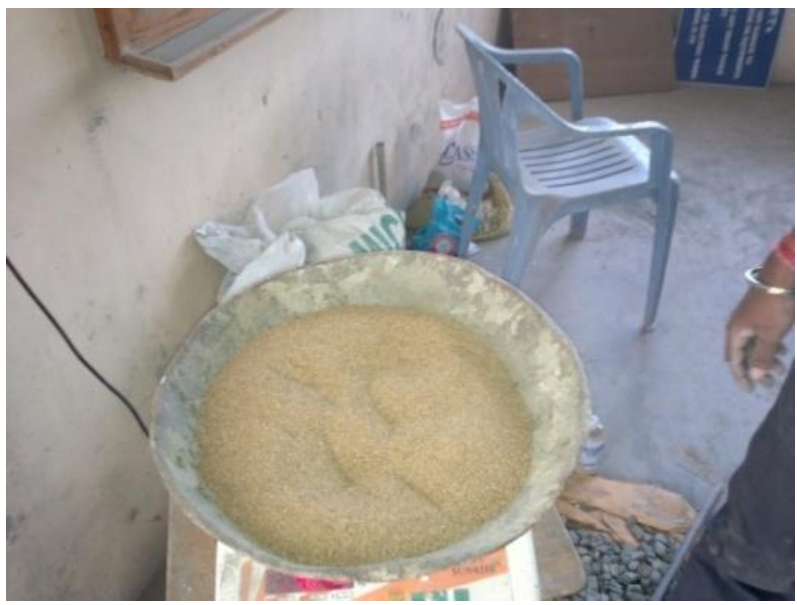

Fig-4: Sieved fine aggregate

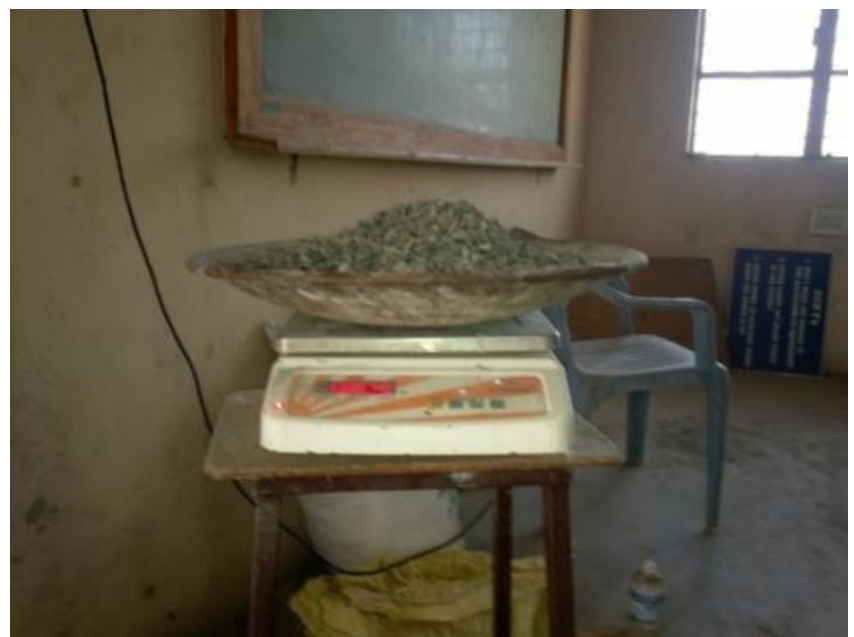

Fig-5: Sieved coarse aggregate

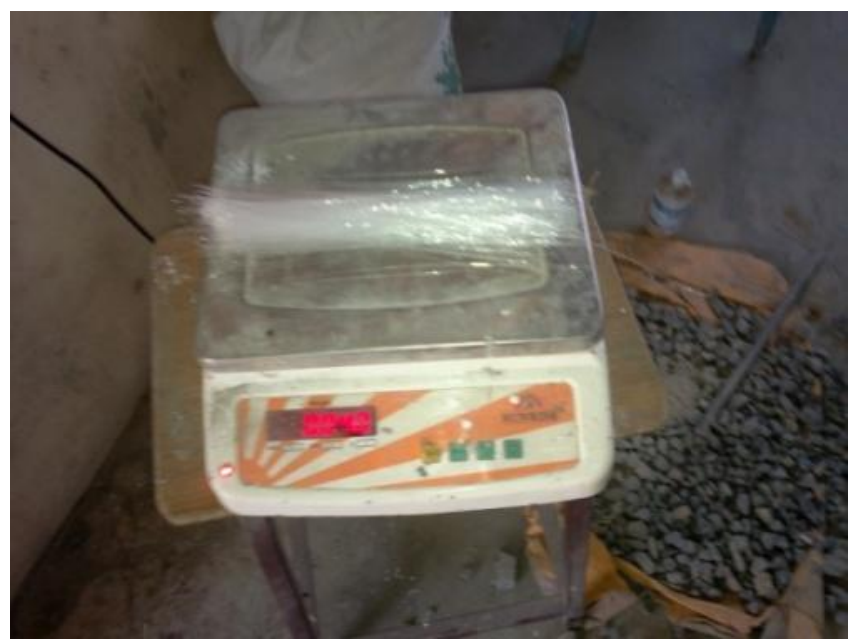

Fig-6: Plastic optic fiber

\subsubsection{Mixing of Materials}

After the batching process, materials are ready to mix. By adding the water using the water cement ratio value the fresh concrete/ cement mortar are made. Fig.5 water

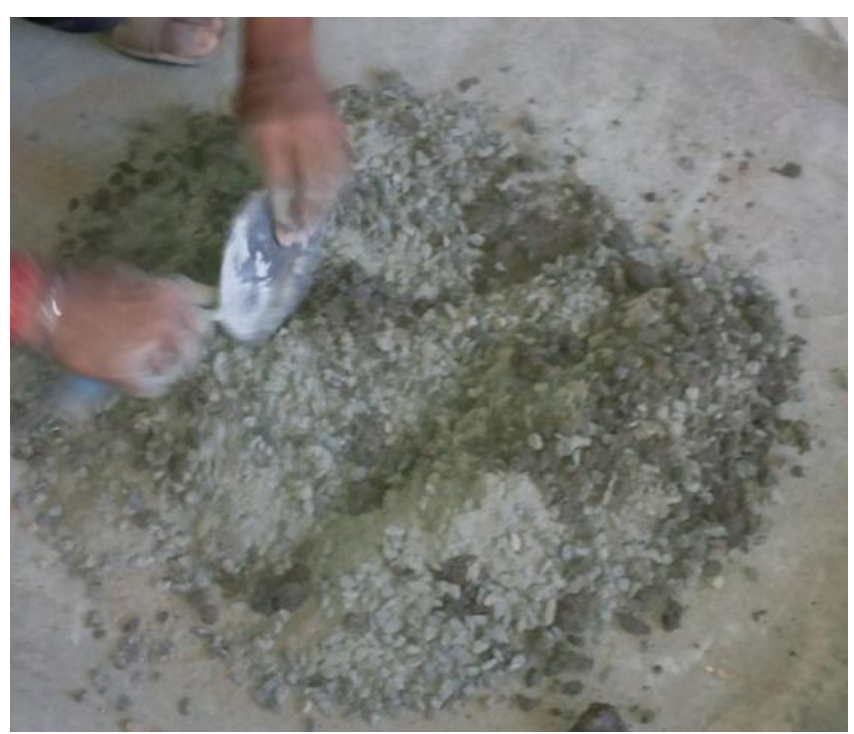

Fig-7: mixing 


\subsubsection{Casting Process}

These blocks are made by the making the alternate layers of concrete and fibres. Fibres layers are placed according to weight proportion of the concrete layer. Due to this simultaneous layers of the fibre, light can be transmit effectively through the concrete. Here, the cement mortar and concrete block contains 20 and 7 layers of pof respectively. In order to achieve the good strength, each layer of concrete and cement mortar are vibrated upto 30 35 and 45 - 50 sec. Respectively

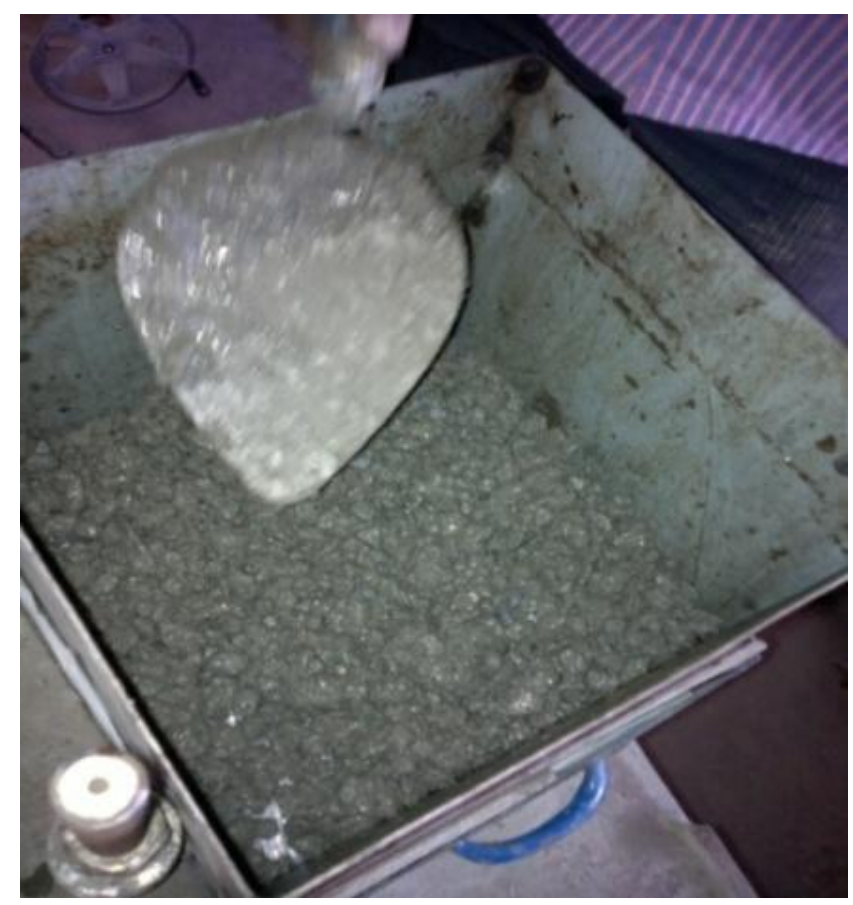

Fig-8: Concrete layer

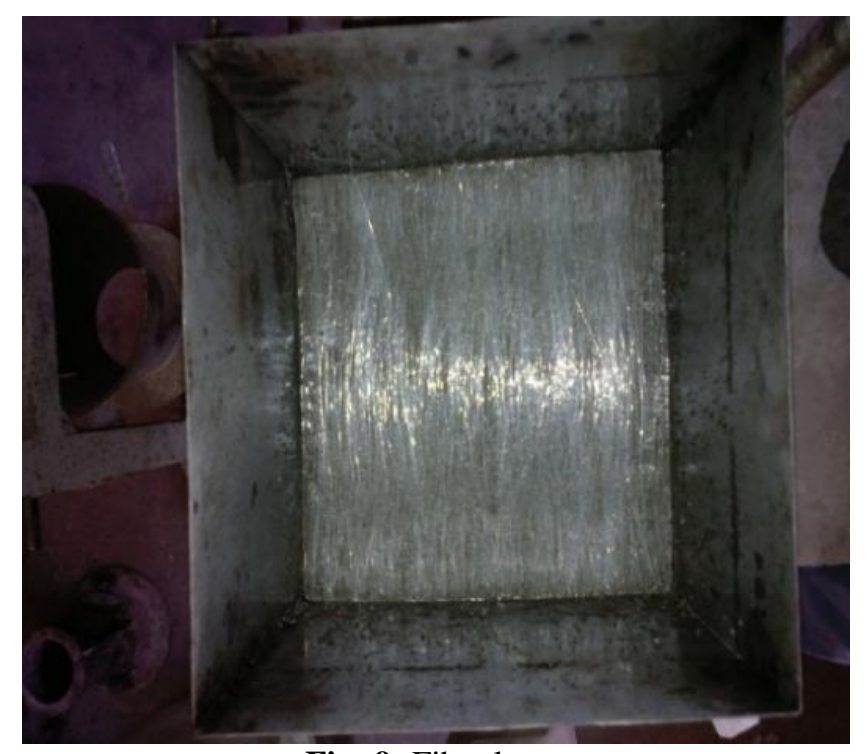

Fig- 9: Fibre layer

\subsubsection{Curing Process}

Once the casting process is completed, the cube is allowed for curing for a particular period. Here the cube is kept for 7 days curing.

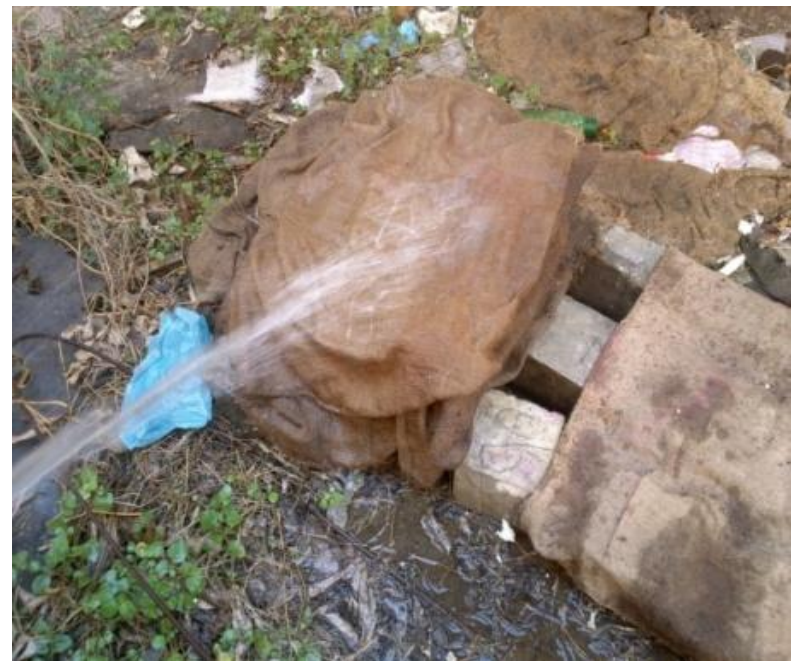

Fig-10: Curing

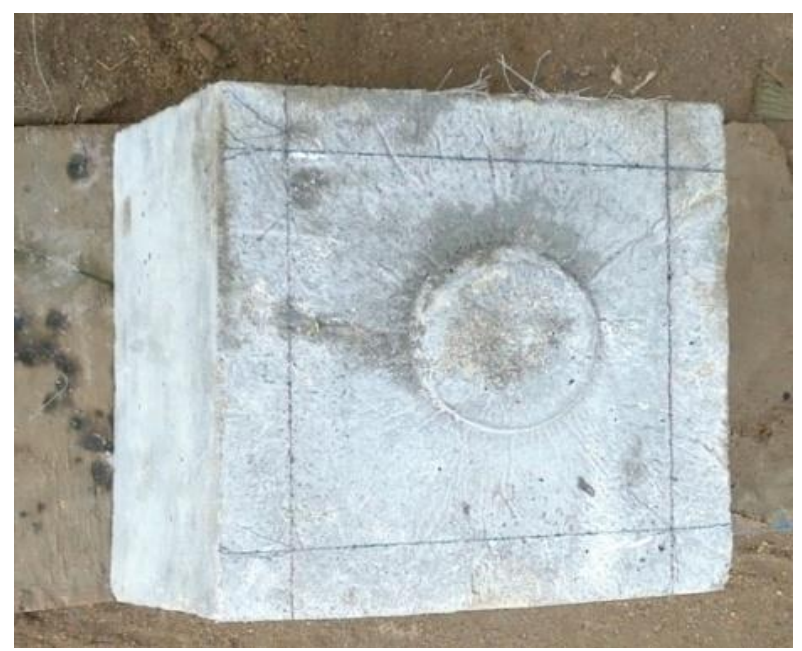

Fig-11: Hardening

\subsubsection{Cutting the Excess Faces}

After the curing process gets completed the cube is taken away from the curing area and allowed to dry the surface of the concrete cube. Then the excess faces are marked for cutting. By using concrete cutting machine, these excess faces are removed and which allows light to transmit from one face to another.

\subsubsection{Final Product}

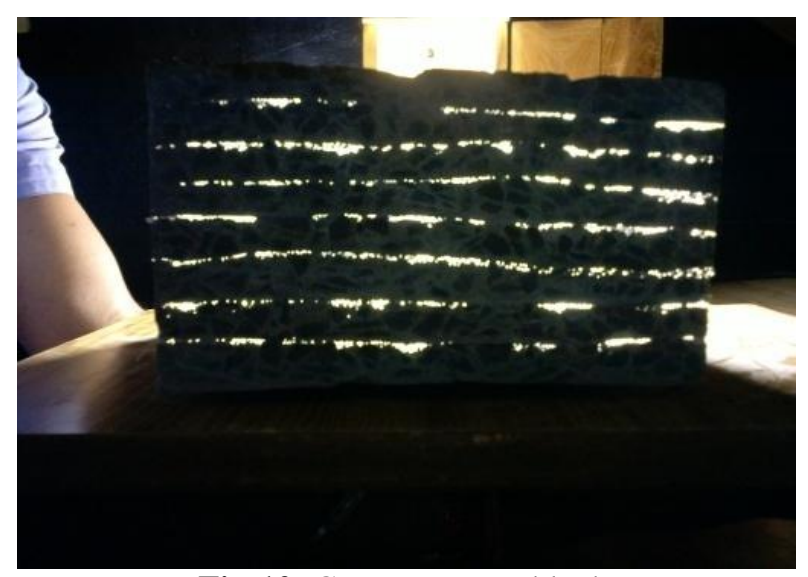

Fig-12: Cement mortar block 


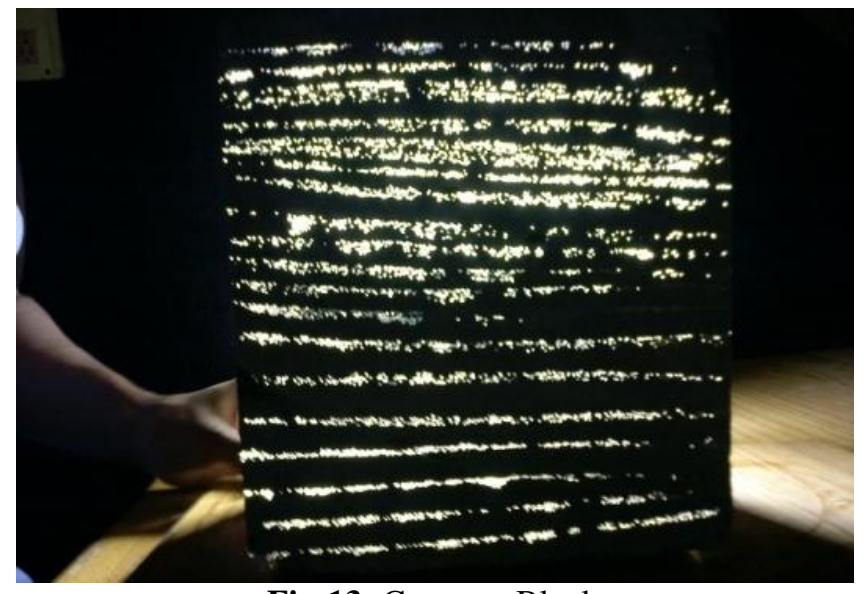

Fig-13: Concrete Block

\section{EXPERIMENTAL ANALYSIS}

\subsection{Compressive Strength Test}

The most common test conducted on hardened concrete is compression test is an easy test to perform and partly because the characteristic properties of concrete is desirably related to its compressive strength.

The test is carried out on specimens likes cubes and cylinder . Prism also sometimes used, but it is not common in our country. Determination of comprerssive strengtyh of concrete using parts of beams used in flexure. To find the compressive strength the end parts of the beam are left intact after failure in flexure and usually square cross section of beam, this part of the beam could be used.

In this project we adopted the addition of $0.5 \%$ and $1 \%$ of pof by its total volume of concrete and a nominal mix without any addition of fibers (0\%).for each percentage we casted 3 cubes inorder to test the cubes after the completion of 14days curing.

\subsection{Experimental Setup to find the Light}

\section{Transmitting Property of Concrete}

The light which transmitted through concrete can can be measured by a photo diode or a light dependent resistors (ldr)

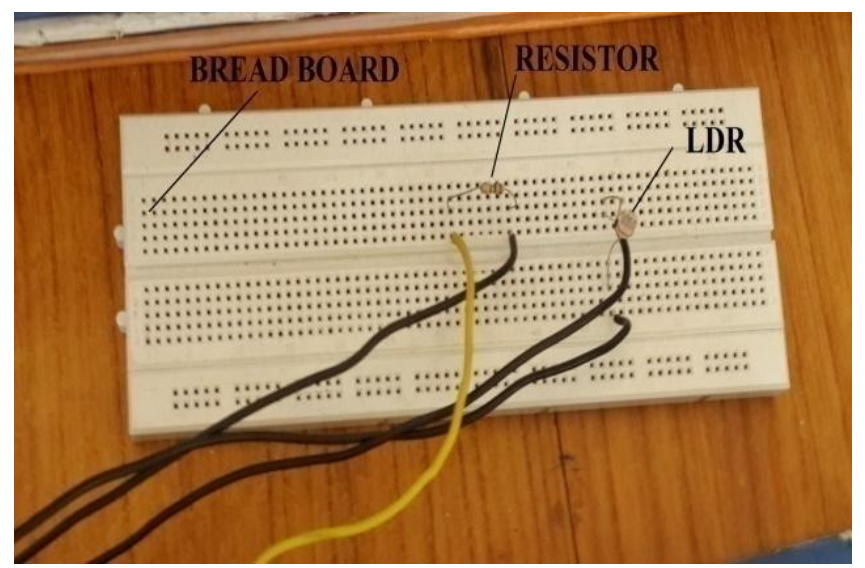

Fig-14: Bread Board

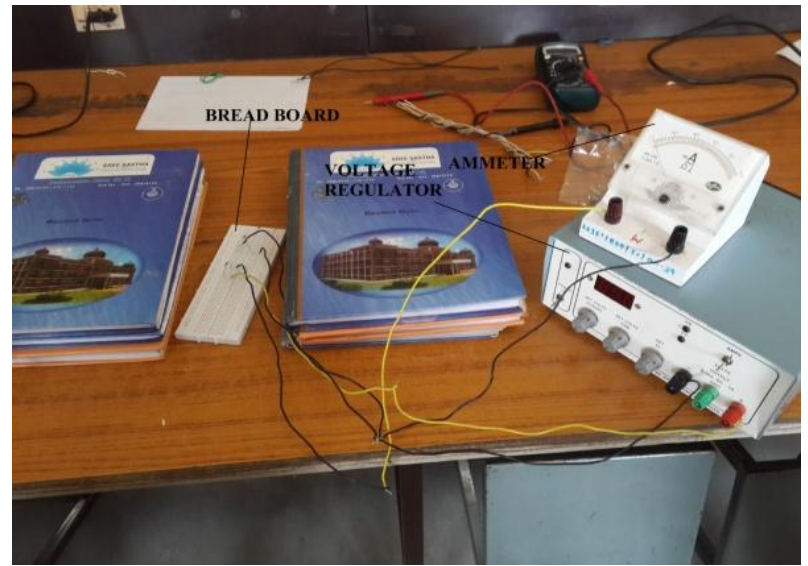

Fig-15: Circuit Setup

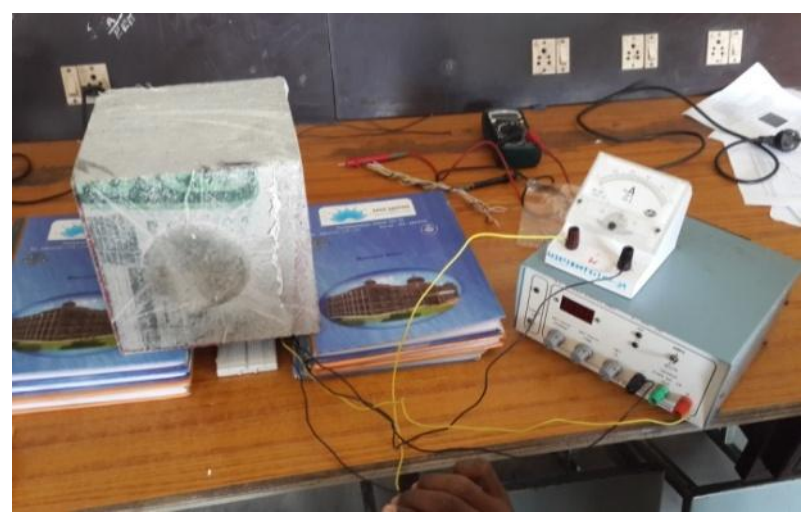

Fig-16 Circuit arrangement

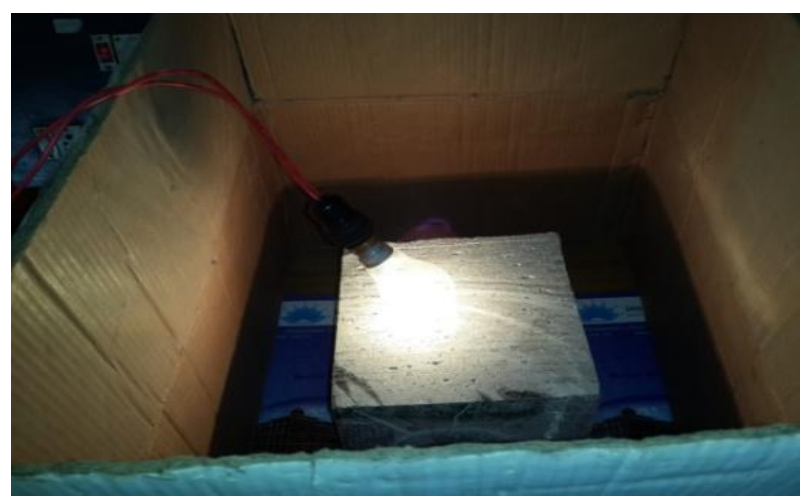

Fig-17 Cardboard setup

[fig shows experimental setup for calculating light transmission property]

A $60 \mathrm{w}$ incandescent bulbs taken here, throughout the test, to ensure no light escapes.

At the top of the specimen light source and at the bottom LDR is placed.Between light and LDR concrete is placed and test is carried out. Reading are taken by differing the voltage.Ttwo values are taken, one without concrete sample (a1) and onewith concrete sample (a2).

Amount of light transmitted is calculated as follows:

Light transmittance $=100-\left[\frac{A 1-A 2}{A 1} \times 100\right]$

Where,

$\mathrm{A}_{1}=$ ammeter reading without specimen.

$\mathrm{A}_{2}=$ ammeter reading with specimen. 


\section{RESULTS AND DISCUSSION}

\subsection{General}

Preliminary test results were stated at the end of each test proceduces and the materials which we used in making the concrete provides satisfactory results during the preliminary test on materials.

In this chapter the major tests results of compressive strength on concrete, cement mortar cubes and light transmitting test are described below

\subsection{Compressive Strength Test On Cement Mortar}

\section{Cubes}

The main purpose of the cement mortar test is to observe the cement - fine aggregate behaviour in paste phase

The main purpose of the cement mortar test is to observe the cement - fine aggregate behaviour in paste phase After 14 days, compressive strength = load/area $=475 \times 10^{3} / 22.5 \times 10^{3}$

$=22.89 \mathrm{n} / \mathrm{mm}^{2}$

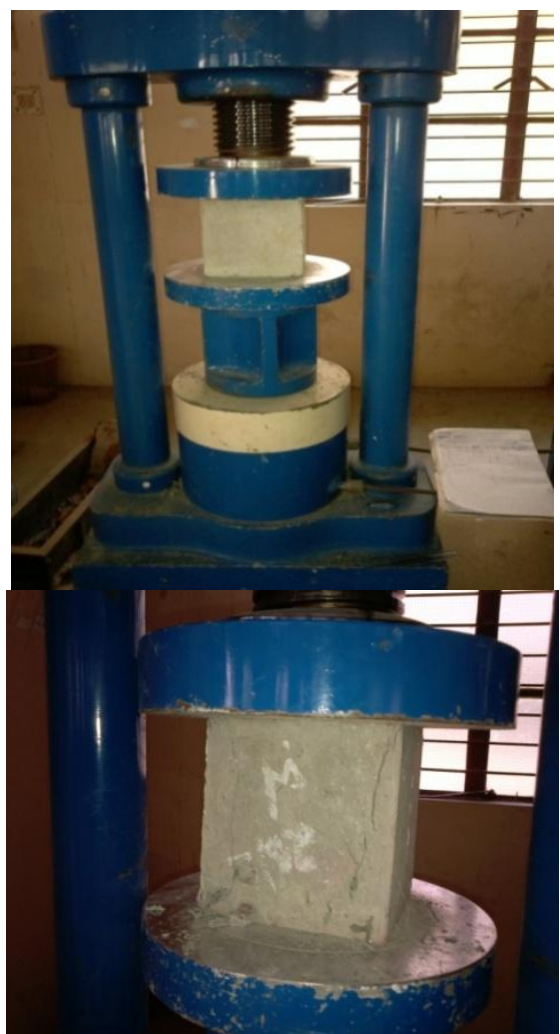

Fig-19 Compression test on cement mortar

Table -1: Compressive test result for cement mortor

\begin{tabular}{|c|c|c|c|}
\hline $\begin{array}{c}\text { Fiber } \\
(\%)\end{array}$ & Specimen a & Specimen b & Specimen c \\
\hline $0 \%$ & $22.89 \mathrm{~N} / \mathrm{mm}^{2}$ & $22.22 \mathrm{~N} / \mathrm{mm}^{2}$ & $22.89 \mathrm{~N} / \mathrm{mm}^{2}$ \\
\hline $0.5 \%$ & $22 \mathrm{~N} / \mathrm{mm}^{2}$ & $20.67 \mathrm{~N} / \mathrm{mm}^{2}$ & $21.33 \mathrm{~N} / \mathrm{mm}^{2}$ \\
\hline $1 \%$ & $19.56 \mathrm{~N} / \mathrm{mm}^{2}$ & $20.89 \mathrm{~N} / \mathrm{mm}^{2}$ & $20.44 \mathrm{~N} / \mathrm{mm}^{2}$ \\
\hline
\end{tabular}

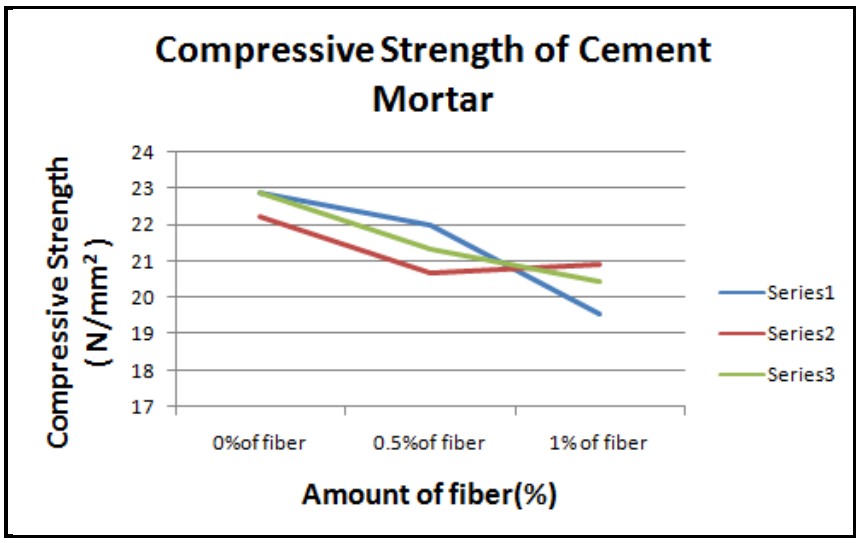

Chart -1 Graph for compressive strength of cement mortar

\subsection{Compressive Strength Test On Concrete Cubes}

The cubes are tested for curing period of 14 days, after the curing process gets completed the cubes are taken away from the curing area and allowed to dry the surface of the concrete cubes only and not the inner portion of the cube, the inner portion should be in a wet state this state is called saturated surface dry condition (ssd). About 18 cubes have been casted in our project and all the cubes are tested in the saturated surface dry condition only.

The accurate strength attained by the concrete is determined only when it is tested in ssd condition, if the concrete specimens are allowed to dry for a long period and it is not tested under ssd conditions, then it shows misleading results, so testing of the specimen under ssd condition is ideal and advisable.

Special attention should also be adopted when placing the concrete cubes in the compressive strength testing machine, as the cubes are placed centrally in the direction of the load application, then the cubes ad broken at the exact failure load, if the cubes get failure at a lower failure load itself, so placing of the specimen in the testing machine also plays a vital role in the testing process.

Test results for $\mathbf{m} 20$ grade:

After 14days

Compressive strength $=$ load $/$ area

$=580 \times 10^{3} / 22.5 \times 10^{3}$

$=23.11 \mathrm{n} / \mathrm{mm}^{2}$

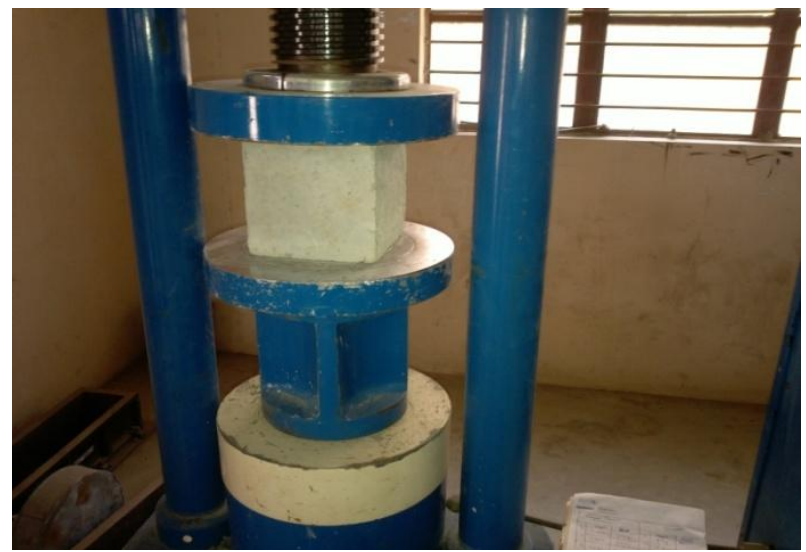

Fig-20 Compression test on concrete 
Table-2 Compressive test result for concrete

\begin{tabular}{|l|l|l|l|}
\hline $\begin{array}{l}\text { Fiber } \\
(\boldsymbol{\%})\end{array}$ & Specimen a & Specimen b & Specimen c \\
\hline $0 \%$ & $26.22 \mathrm{n} / \mathrm{mm}^{2}$ & $24.44 \mathrm{n} / \mathrm{mm}^{2}$ & $25.78 \mathrm{n} / \mathrm{mm}^{2}$ \\
\hline $0.5 \%$ & $24 \mathrm{n} / \mathrm{mm}^{2}$ & $23.56 \mathrm{n} / \mathrm{mm}^{2}$ & $24 \mathrm{n} / \mathrm{mm}^{2}$ \\
\hline $1 \%$ & $23.11 \mathrm{n} / \mathrm{mm}^{2}$ & $21.77 \mathrm{n} / \mathrm{mm}^{2}$ & $22.66 \mathrm{n} / \mathrm{mm}^{2}$ \\
\hline
\end{tabular}

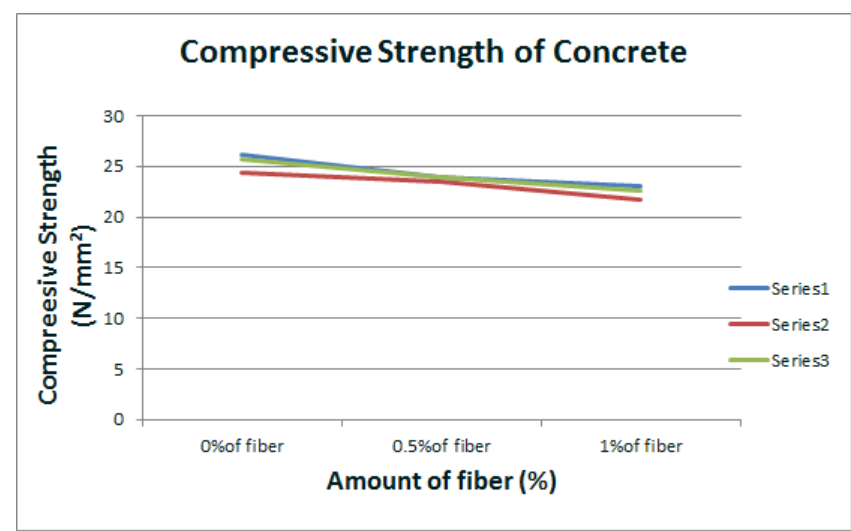

Chart-2 Graph for compressive strength of concrete

\subsection{Light Transmission Results on Cement Mortar and Concrete Blocks}

Table -3: Test result for light transmission

\begin{tabular}{|c|c|c|c|c|c|}
\hline \multirow{2}{*}{$\begin{array}{c}\text { Input } \\
\text { voltage } \\
(\mathbf{v})\end{array}$} & \multicolumn{5}{|c|}{ Output } \\
\cline { 2 - 6 } & $\begin{array}{c}\text { Without } \\
\text { specimen }\end{array}$ & \multicolumn{2}{|c|}{ Cement mortar } & \multicolumn{2}{c|}{ Concrete } \\
\cline { 2 - 6 } & $\begin{array}{c}\text { Current } \\
(\mathbf{m a})\end{array}$ & $\begin{array}{c}\text { Current } \\
(\mathbf{m a})\end{array}$ & $\begin{array}{c}\text { Light } \\
(\%)\end{array}$ & $\begin{array}{c}\text { Current } \\
(\mathbf{m a})\end{array}$ & $\begin{array}{c}\text { Light } \\
(\%)\end{array}$ \\
\hline 5 & 10 & 1 & 10 & 0.6 & 6 \\
\hline 10 & 20 & 1.5 & 7.5 & 0.9 & 4.5 \\
\hline 15 & 32 & 2 & 6.25 & 1.25 & 3.9 \\
\hline 20 & 44 & 2.5 & 5.6 & 1.5 & 3.4 \\
\hline 25 & 60 & 3 & 5 & 2 & 3.3 \\
\hline
\end{tabular}

Calculation of light transmittance as follows:

Transmittance of light $=100-\left[\frac{A 1-A 2}{A 1} \times 100\right]$

Where, $a_{1}=$ ammeter reading without specimen.

$\mathrm{a}_{2}=$ ammeter reading with specimen

\section{Comparison of Light Transmission}

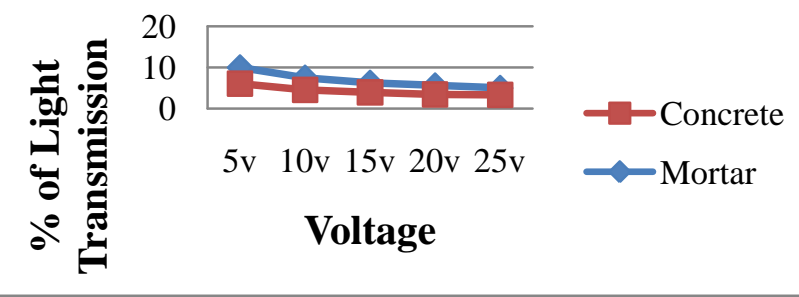

Chart-3: Graph for comparison of light transmission.

\section{CONCLUSION}

A conclusion can be made by the experimental investigation.

- A translucent cement mortar block compressive strength was to be as same as the normal concrete strength .

- A translucent concrete block compressive was to be as same as the normal strength for $\mathrm{m} 20$ grade concrete.

- translucent was found to 5 to $10 \%$ in cement mortar blocks and 3 to $6 \%$ in concrete blocks.

- The transparency of the cement mortar block with plastic fibre optics as compared to the concrete block with plastic fibre optics and more the transparency of the material more will be the light transmittance through the sample.

- It concludes that the translucent concrete transmits the light without out affecting its compressive strength, as the plastic optical fibers are embedded through it, there by enhancing the strength and also enhances appearance.

\section{REFERENCES}

[1] m.n.v. Padma bhushan et.al "optical fibers in the modeling of translucent concrete blocks" international journals of engineering research and application, issn: 2248 - 9622. Vol.3, issue 3, may - june 2013.

[2] prof.a.a.momin et.al "study on light transmittance of concrete using optical fiber and glass rods".iosr journal of mechanical and civil engineering .

[3] bhavink.kashiyani, et.al "a study on transparent concrete : a novel architectural material to explore construction sector " international journal of engineering and innovative technology.

[4] akshayab.kamdi"transparent concrete as a green material for building"international journal of structural and civil engineering research issn 2319 - 6009. Vol. 2, no.3, august 2013 .

[5] soumyajit paul and avikdutta "translucent concrete" international journal of scientific and research publications, volume 3, issue 10, october 2013.

[6]jianpingheet.al "study on smart transparent concrete product and its performances" the $6^{\text {th }}$ international workshop on advanced smart materials and smart structures technology.july $25-26,2011$, dalian, china.

[7] basma f. Bashbash et.al "basics of light transmitting concrete" global advanced research journal of engineering, technology and innovation (issn:2315-5124) vol.2(3) pp.076-083, march, 2013.

[8] nehar.nagdive\&shekard.bhol"to evaluate properties of translucent concrete / mortar \& their panels" international journal of research in engineering \& technology (impact:ijret) issn(e) : 2321-8843; issn(p):2347-4999, vol.1. Issue 7, dec 2013, 23-30.

\section{Indian Standard Codes}

Is 456:2000 "plain and reinforced concrete code of practice" Is 10262:1989 "recommended guidelines for concrete mix design"

Is 10262:2009 "concrete mix proportioning" 